\title{
SENSITIVITY COMPARISON OF ELISA AND RAPID SCREENING TECHNIQUES FOR THE DETECTION OF HBSAg AMONG CHRONIC LIVER DISEASE (CLD) PATIENTS IN A TERTIARY CARE HOSPITAL, SOUTH BIHAR, INDIA
}

\author{
Imtiaz Ahmad', Asim Mishra², Chandan Kumar Poddar³, Pawan Kumar Chaudhary4, Maheshwar Narayan Singh ${ }^{5}$
}

${ }^{1}$ Assistant Professor, Department of Pathology, Vardhman Institute of Medical Sciences, Pawapuri, Nalanda.

${ }^{2}$ Associate Professor, Department of Pathology, Anugrah Narayan Magadh Medical College, Gaya.

${ }^{3}$ Research Scholar, Department of Microbiology, Indira Gandhi Institute of Medical Sciences, Patna.

${ }^{4}$ Associate Professor and HOD, Department of Pathology, Vardhman Institute of Medical Sciences, Pawapuri, Nalanda.

5 Professor, Department of Microbiology, Anugrah Narayan Magadh Medical College, Gaya.

\section{ABSTRACT}

\section{BACKGROUND}

Hepatitis B is a major health problem in India. Based on the prevalence of hepatitis B carrier in India is the intermediate endemic level of hepatitis B surface antigen (HBsAg). This study aims to determine the frequency of HBV by screening of chronic liver disease (CLD) patients. This study also aims to compare the sensitivity between two diagnostic tests; one step rapid test strip device (RIA) and Enzyme Linked Immunosorbent Assay (ELISA).

\section{MATERIALS AND METHODS}

A cross-sectional study was carried out in adult patients with liver disease attending the Hepatology OPD, Tertiary Care Hospital in Nalanda (Bihar), India. Age, gender and clinical history of the patients were recorded. Blood specimen was screened for Hepatitis B surface Antigen (HBsAg) using one step rapid test strip device and Enzyme Linked Immunosorbent Assay (ELISA).

\section{RESULTS}

Five hundred patients were enrolled in the study. The mean age of infected patients in the study group was $37.7 \pm 1.32$ years (range 19 to 76 years). Of the 500 samples tested, 18.4\% were positive for HBsAg by HEPA-SCAN HBsAg ELISA Test and 13.4\% were positive by Hepacard one step rapid test. Considering the results of HEPA-SCAN HBsAg ELISA Test, the sensitivity, specificity, PPV and NPV of ELISA were 97.87\%, 99.75\%, 98.92\% and 99.51\% respectively. The sensitivity, specificity, PPV and NPV of Hepacard one step rapid test were $97.10 \%, 99.76 \%, 98.52 \%$ and $99.54 \%$ respectively.

\section{CONCLUSION}

This study shows that frequency of HBV is high in India and the incidence is greater in males than the females. We also noted that in comparing both methods (ELISA method and the rapid test strip) for assessing the presence of HBsAg, ELISA test method was found to be more sensitive than the rapid test strip device. Therefore, we recommend strongly, that ELISA method be used to confirm test results obtained from the one step rapid test, when screening for chronic liver disease (CLD).

\section{KEYWORDS}

Chronic Liver Disease, ELISA Methods, Hepatitis B, Rapid Test Strip.

HOW TO CITE THIS ARTICLE: Ahmad I, Mishra A, Poddar CK, et al. Sensitivity comparison of ELISA and rapid screening techniques for the detection of HBsAg among chronic liver disease (CLD) patients in a tertiary care hospital, south Bihar, India. J. Evolution Med. Dent. Sci. 2017;6(71):5045-5049, DOI: 10.14260/Jemds/2017/1097

\section{BACKGROUND}

Hepatitis B Virus, which causes serious liver damage is one of the WHO's target for global eradication by 2020.[1] It is a major public health problem worldwide and is more prevalent in the developing countries.[2,3] More than 2 billion people are infected with HBV worldwide while some 280 million are chronic carriers, harbouring the virus in their liver.[4]

Hepatitis B is a major health problem in India. Based on the prevalence of hepatitis B carrier state in the general

Financial or Other, Competing Interest: None.

Submission 20-07-2017, Peer Review 22-08-2017,

Acceptance 28-08-2017, Published 04-09-2017.

Corresponding Author:

Dr. Chandan Kumar Poddar,

Research Scholar,

Department of Microbiology,

Indira Gandhi Institute of Medical Sciences,

Patna.

E-mail: chandan_microbiology@yahoo.co.in

DOI: $10.14260 /$ jemds $/ 2017 / 1097$ population, countries are classified as having high $(8 \%$ or more), intermediate (2-7\%), or low (less than $2 \%$ ) HBV endemicity. India is at the intermediate endemic level of hepatitis B, with hepatitis B surface antigen (HBsAg) prevalence between $2 \%$ and $10 \%$ among the populations studied. The prevalence does not vary significantly by region in the country. The number of HBsAg carriers in India has been estimated to be over 40 million ( 4 crore). Hepatitis B is one of the major diseases of mankind and is a serious global public health problem. Of the 2 billion people who have been infected with the hepatitis B virus (HBV) in the world, more than 360 million have chronic (lifelong) infections. These chronically infected people are at high risk of death from cirrhosis of the liver and liver cancer, diseases that kill about one million each year. In India, of the 25 million infants born every year, over one million run the lifetime risk of developing chronic HBV infection. Estimates indicate that annually over 100,000 Indians die due to illnesses related to HBV infection.[5] Hepatitis B Virus (HBV) infection is a global public health problem. It is estimated that approximately 360 million people are infected worldwide with the virus.[6] Viral 
hepatitis is a systemic disease primarily involving the liver. Most of the cases of acute viral hepatitis are caused by Hepatitis A (HAV), Hepatitis B (HBV) or Hepatitis C Viruses (HCV). HBV has a double standard DNA encoding for $\mathrm{P}, \mathrm{X}$, core and surface proteins. The complex antigen found on the surface of HBV is called Hepatitis B surface antigen (HBsAg). Antibodies against HBV proteins are other immunological markers of infection, of which Anti-Hepatitis B core antigen, Hepatitis B envelope antigen and Hepatitis B envelope antibody are also identified shortly after HBsAg, and are important markers of past or present HBV infection. In a typical Hepatitis B infection, Hepatitis B surface antigen (HBsAg) will be detected within 2 to 5 weeks before symptoms or jaundice develop. [7]

Presently, both serological and molecular screening tests are employed for the diagnosis and patient monitoring of HBV infection. Nucleic acid test (NAT) is preferable in terms of its simplicity, rapidness and sensitivity but in some cases of occult HBV especially, NAT may miss some positive samples. NAT has the ability to decrease window period. However, it has been shown that NAT is too costly for testing individual samples. ${ }^{[8]}$ Among all HBsAg assays, ELISA techniques are the most frequently used because of their effectiveness. In many developed countries, HBsAg screening is usually done with ELISA techniques.[9] Blood transfusion services are a vital part of modern health care system, with every unit of blood there is $1 \%$ chance of transfusion associated problem including transfusion transmittable diseases. Transfusing infected blood to unsuspected patients in need is a crime. It is mandatory to test each and every unit of donor blood for antibodies to HIV-1 and HIV-2, syphilis, HBsAg and HC Virus. ELISA is the recommended and preferred screening technique for blood banking.[10] Many blood banks still do not have this facility and rather prefer rapid screening kits because they are easy to perform, cheap and are user friendly kits, and do not require sophisticated equipment and elaborate training. A preliminary study was therefore conducted to evaluate the efficacy of these rapid testing kits for screening of blood donors.[11] HBsAg rapid test srip is a rapid screening test for the qualitative detection of HBsAg in whole blood, serum or plasma specimen. The test utilises a combination of monoclonal and polyclonal antibodies to selectively detect elevated levels of HBsAg in whole blood, serum or plasma.[12] Enzyme-linked Immunosorbent Assay (ELISA) is an enzymatic immunoassay technique of the "sandwich" type for the detection of Hepatitis B virus in human serum or plasma. The test uses monoclonal antibodies selected for their ability to bind themselves to the various sub-types of HBsAg now recognised by the World Health Organization (WHO) and the most part of variant HBV strains. $[13,14]$

The present study was hence carried out to find out the prevalence of HBsAg in liver disease patients and to compare the routinely Central Pathology Section used HBsAg detection kit using Hepacard one step rapid test with the ELISA for invitro qualitative detection of HBsAg test kit in human serum (HEPA-SCAN HBsAg ELISA Test was used).

\section{MATERIALS AND METHODS \\ Study Design}

A cross-sectional study was carried out in adult patients with liver disease attending the Hepatology OPD, Tertiary Care Hospital in Nalanda, (Bihar), India after obtaining institutional ethics committee approval over a period of Two years from January 2015 to January 2017. All the consecutive patients during the study period who were above 18 years of age and gave written informed consent were included in the study. Age, gender and clinical history of the patients were recorded in the case record form after obtaining written informed consent.

\section{Patient's Inclusion Criteria}

This study included a total of five hundred (500) patients enrolled in the study. The mean age of infected patients in the study group was $37.7 \pm 1.32$ years (range 19 to 75 years). i.e. a cohort study of selected chronic liver disease (CLD) patients visiting the Hepatology OPD, Vardhman Institute of Medical Sciences, Pawapuri, Nalanda, Bihar and Associated Hospital of Bihar between January 2015 and January 2017. The inclusion criteria for the selection of the CLD patients used for this study were presence of jaundice, ascites, hepatomegaly and oedema.

This prospective study was conducted in the Department of Pathology, Vardhman Institute of Medical Sciences, Pawapuri and Associated Hospital of Bihar, India from January 2015 to January 2017. The 500 serum/plasma samples were screened using Hepacard one step rapid test for the detection of hepatitis B surface antigen (HBsAg) (Manufactured by Diagnostic Enterprises, Plot no.26, Indl. Estate, Sector -1, Parwanoo-173220, HP). It is a rapid immunochromatographic assay designed for qualitative determination of HBsAg in human serum. It is for in-vitro diagnostic use with sensitivity of $97.10 \%$ and specificity of 99.76\%

\section{Detection of HBsAg using ELISA Method}

The 500 subjects were also screened using ELISA method for hepatitis B. The ELISA test is a solid-phase microtitre plate coated with monoclonal antibodies to human IgM which is based on sandwich principle. ELISA for in-vitro qualitative detection of HBsAg test kit in human serum (HEPA-SCAN HBsAg ELISA Test) was used. It is for in-vitro qualitative detection use with sensitivity of $97.87 \%$ and specificity of 99.75\%.

\section{Statistical Analysis}

The $\mathrm{X}^{2}$ (Chi-square) test and analysis using the statistical software (SPSS version 18) was performed for quantitative variables to check for relationship in detecting HBV infection. Percentages were calculated directly for HBV infection. $\mathrm{P}=$ 0.05 was used as the accepted significance level.

\section{RESULTS}

Five hundred patients were enrolled in the study. The prevalence of HBsAg was found to be $17.8 \%$. The mean age of infected patients in the study group was $37.7 \pm 1.32$ years (range 19 to 76 years). Three hundred and Forty six $(69.22 \%)$ were male and One hundred and Fifty four (30.78\%) were female. The positivity amongst the male population was $18.20 \%$ which was higher than the female population $(15.58 \%)$, but the difference was statistically significant $(\mathrm{p}=0.05)$ [Table-1].

Most of the CLD patients were in the age group of 19 - 30 years of age $28.26 \%$ followed by $35.86 \%$ in $31-45$ years, $30.43 \%$ in $46-60$ years and $5.43 \%$ in $61-75$ (Table 1) 
(Graph No. 1). Seroprevalence of HBV among 500 CLD patients in present study was $18.4 \%$. HBV infection was seen mostly in the age group of 31 - 45 yrs. (35.86\%) (Chart Table No. 2).

Of the 500 samples tested, $18.4 \%$ were positive for HBsAg by HEPA-SCAN HBsAg ELISA Test [Fig-1] and $13.4 \%$ were positive by Hepacard one step rapid test [Fig/Table-2] [Chart Table-1]. Considering the results of HEPA-SCAN HBsAg ELISA Test, the sensitivity, specificity, PPV and NPV of ELISA were $97.87 \%, 99.75 \%, 98.92 \%$ and $99.51 \%$ respectively. The sensitivity, specificity, PPV and NPV of Hepacard one step rapid test were $97.10 \%, 99.76 \%, 98.52 \%$ and $99.54 \%$ respectively. (Table-4)

Education level of $34.74 \%$ of the study participants were illiterate, $32.60 \%$ had primary education, $10.86 \%$ had upto secondary education and $27.17 \%$ were upto high school. Only $5.43 \%$ were graduates. HBV infection was maximum in illiterates $32 / 92(34.74 \%)$ and patients having education upto primary level 30/92 (32.60\%) (Table 3).

\begin{tabular}{|c|c|c|}
\hline Age & Number & Positive (\%) \\
\hline $19-30$ & 76 & $26(28.26)$ \\
\hline $31-45$ & 216 & $33(35.86)$ \\
\hline $46-60$ & 178 & $28(30.43)$ \\
\hline $61-75$ & 30 & $5(5.43)$ \\
\hline Male & 346 & $66(19.07)$ \\
\hline Female & 154 & $26(16.88)$ \\
\hline Table 1. Age and Gender Wise Distribution of Patients \\
\hline
\end{tabular}

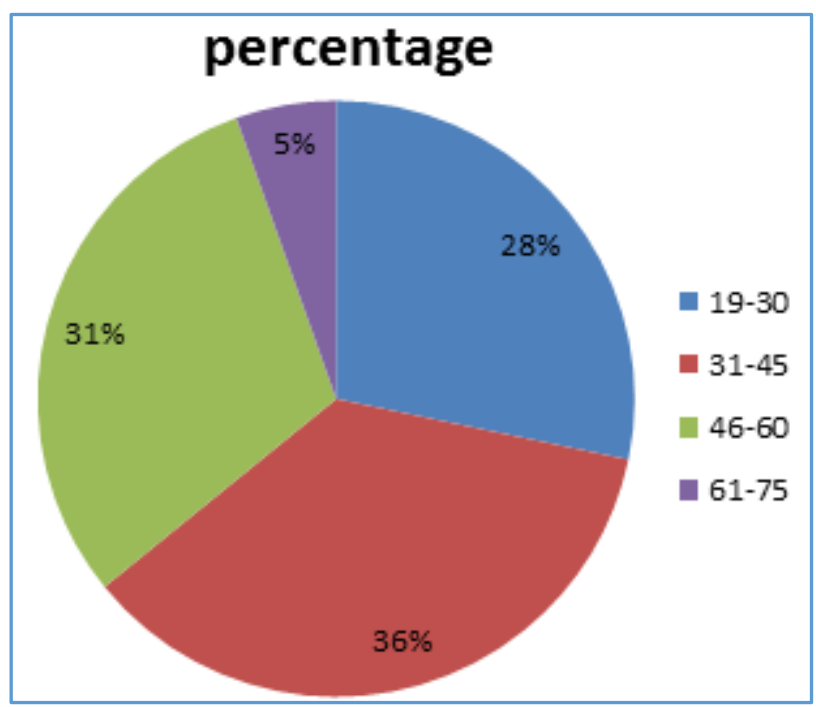

Graph 1. Percentage of Age Groups

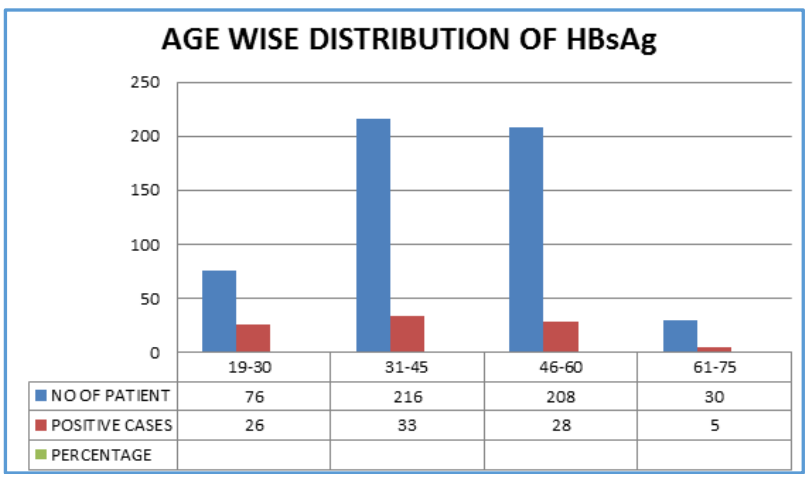

Chart 1. Age Wise Distribution of HBsAg Positive

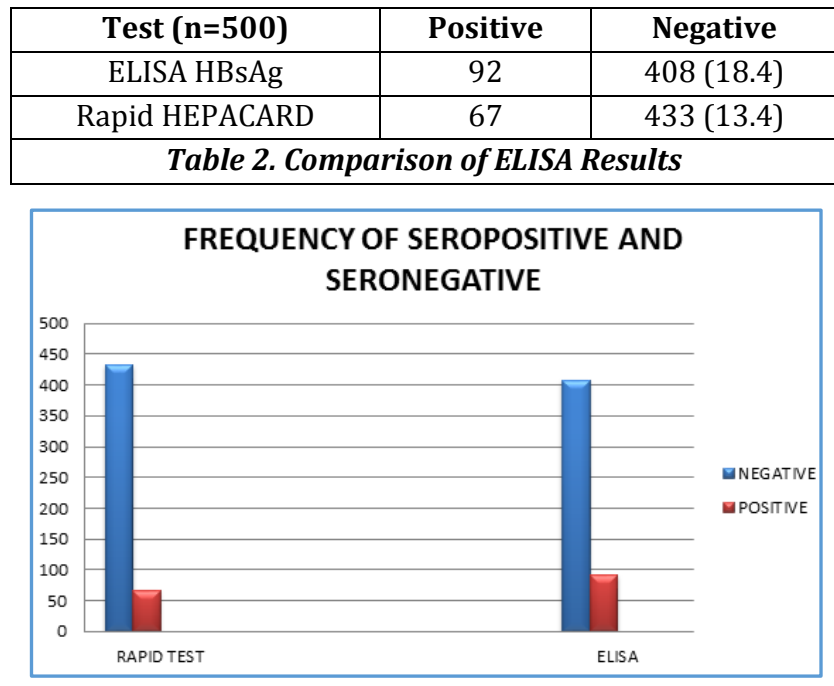

Chart 2. Frequency of Seropositivity and Seronegativity according to the different Methods used for HBsAg Detection

\begin{tabular}{|c|c|c|c|c|}
\hline $\begin{array}{c}\text { Educational } \\
\text { Status }\end{array}$ & $\begin{array}{c}\text { CLD } \\
\text { NO }\end{array}$ & $\begin{array}{c}\text { CLD } \\
\mathbf{\%}\end{array}$ & $\begin{array}{c}\text { HBV +ve } \\
\text { NO }\end{array}$ & $\begin{array}{c}\text { HBV +ve } \\
\mathbf{\%}\end{array}$ \\
\hline Illiterate & 125 & 25 & 32 & 34.78 \\
\hline Primary school & 175 & 35 & 30 & 32.60 \\
\hline Secondary school & 100 & 20 & 10 & 10.86 \\
\hline High school & 60 & 12 & 15 & 16.30 \\
\hline Graduate & 40 & 8 & 5 & 5.43 \\
\hline Total & $\mathbf{5 0 0}$ & $\mathbf{1 0 0}$ & $\mathbf{9 2}$ & $\mathbf{1 0 0}$ \\
\hline Table 3. Educational Status of HBsAG Patients \\
\hline
\end{tabular}

\begin{tabular}{|c|c|c|}
\hline & $\begin{array}{c}\text { HEPA-SCAN } \\
\text { HBsAg ELISA (\%) }\end{array}$ & $\begin{array}{c}\text { Hepacard One } \\
\text { Step Rapid } \\
\text { Test (\%) }\end{array}$ \\
\hline Sensitivity & $97.87 \%$ & $97.10 \%$ \\
\hline Specificity & $99.75 \%$ & $99.76 \%$ \\
\hline $\begin{array}{c}\text { Positive Predictive } \\
\text { Value (PPV) }\end{array}$ & $98.92 \%$ & $98.52 \%$ \\
\hline $\begin{array}{c}\text { Negative Predictive } \\
\text { Value (NPV) }\end{array}$ & $99.51 \%$ & $99.54 \%$ \\
\hline
\end{tabular}

Table 4. Sensitivity Comparison of ELISA and Rapid Screening Techniques for the Detection of HBsAg among Chronic Liver Disease (CLD) patients when ELISA was taken as Gold Standard

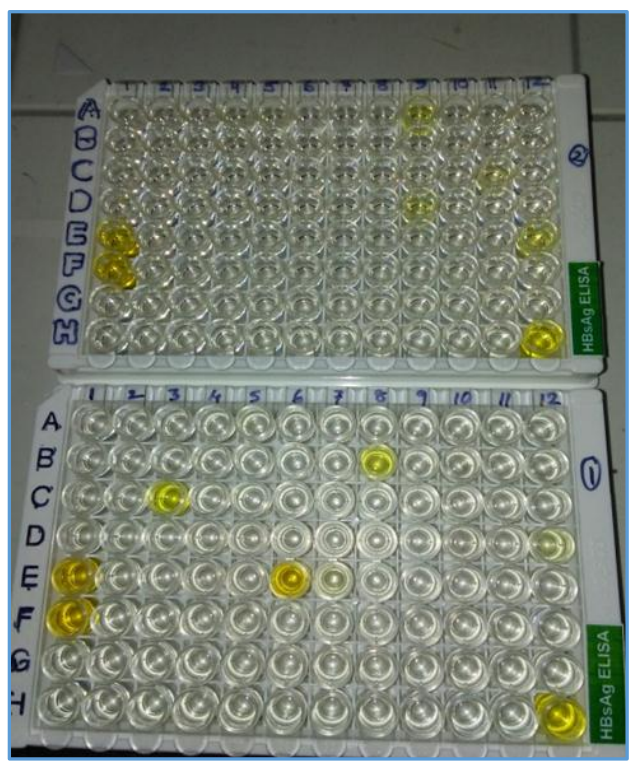

Figure 1. HEPA-SCAN HBsAg ELISA Test 


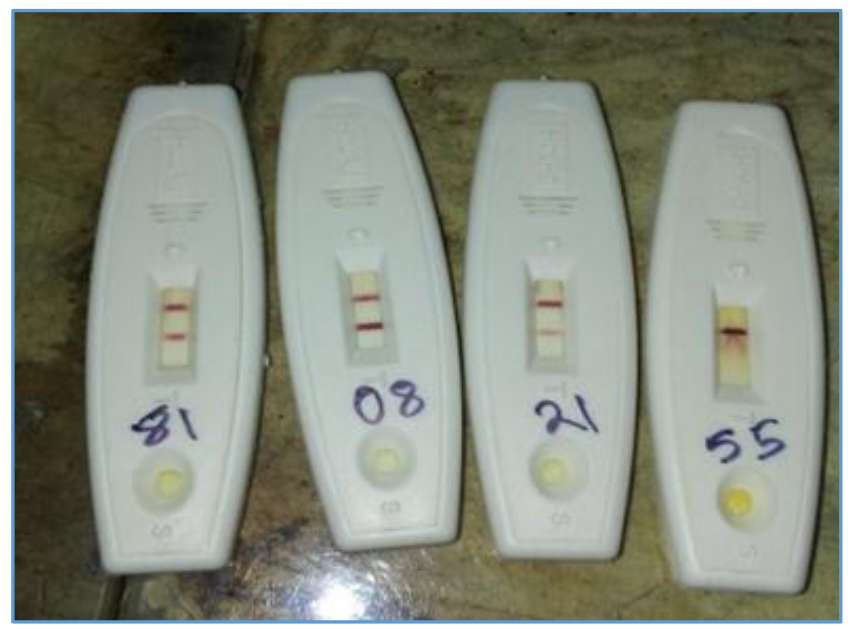

Figure 2. Hepacard One Step Rapid Test

\section{DISCUSSION}

It is estimated by the World Health Organisation that there are about 350 million chronic carriers of hepatitis B spreading in every continent in Asia, America, Europe and Africa: $[15,16]$ In this study, two methods were used (rapid strip test device and ELISA test) to check for sensitivity in screening for hepatitis B surface antigen among chronic liver disease patients. A percentage of the subjects (97.87\%) tested positive using ELISA method while $97.10 \%$ tested positive using the rapid test strip

Viral hepatitis is the most common cause of chronic liver disease throughout the world.[17, 18] In India, HBV is reported to be responsible for $70 \%$ of chronic hepatitis cases and $80 \%$ of cirrhosis of liver cases.[19] The mean age of the infected subjects in the present study was 43 years which is in concordance with a study published by Arora and Mann.[20] Nayak et al in their study have suggested that $30 \%$ of chronic carriers get infected vertically and remaining get infection horizontally from those who got it vertically.[21]. The chances of horizontal infection occurring through close contact with carriers, use of unsafe injections, and an association with a number of sociocultural practices increases with advancing age. Hepatitis B vaccination became available in 1981 and has been included in the Universal Immunization Program in India as late as 2007 - 2008. This has contributed significantly in reducing the prevalence thereafter.[22] However, in the present study, the prevalence of Hepatitis B infection gradually decreased with age from $34.9 \%$ in $19-30$ years age group to $13.4 \%$ in patients older than 45 years of age. This possibly could be due to the other causes of chronic liver disease in older age group [Table/Fig-1]. HBsAg prevalence in men was higher $(18.20 \%)$ as compared to women $(15.58 \%)$ in the present study. A similar higher prevalence in men has also been reported by Abdool Karim et al.[23] Though no specific reasons can be attributed to the higher prevalence in men, it could possibly be due to a higher exposure risk in this population or because more male population seeks health care.[24, 25] In our study, $17.8 \%$ of patients with liver disease had hepatitis B infection which is similar to the study by Kumar et al, (17.34\%).[26] Other studies in India have reported HBsAg detection rate varying between $12.2-51 \%$ in liver disease patients.[19, 20, 26, 27] The difference in prevalence rate in a given region is dependent on the degree of endemicity in that region. The higher prevalence in the present study as compared to that in the general population is expected since the patients enrolled were liver disease patients attending the Hepatology OPD with majority having symptoms like jaundice, anorexia, nausea, vomiting, and haematemesis.

A high frequency rate has been seen in ELISA method when compared to rapid strip test device. So, there is a great and urgent need for people in this locality and beyond to screen their blood for HBV and it should be screened using the ELISA technique which has been found to be more sensitive and accurate as compared to the rapid test strip device method.

\section{CONCLUSION}

This study shows that frequency of HBV is high in India and the incidence is greater in males than the females. We also noted that in comparing both methods (ELISA method and the rapid test strip) for assessing the presence of HBsAg, ELISA test method was found to be more sensitive than the rapid test strip device. Therefore, we recommend strongly, that ELISA method be used to confirm test results obtained from the one step rapid test, when screening for chronic liver disease (CLD).

\section{REFERENCES}

[1] Dusheiko GM, Khakoo S, Soni P, et al. A national approach to the management of Hepatitis C infection. British Medical Journal 1999;312:351-64.

[2] Peter H, Tokyo O. Hepatitis B and its incubation period 2000. http/www/scientistsmagTech.org.

[3] World Health Organization (WHO). Hepatitis B. http: www.none who.inf/inffs /en/fact204.html.

[4] Johnson AOK, Sodeinde O, Odeola HA, et al. Survey of Hepatitis A and B infections in childhood in Ibadan preliminary 8 study. Nigeria Journal of Paediatrics 1986;13:83-6.

[5] Agarwal R, Naik SR. Prevention of hepatitis B infection: the appropriate strategy for India. Natl Med J India 1994;7(5):216-20.

[6] Chen DS. Toward elimination and eradication of Hepatitis B. J Gastroenterol Hepatol 2010;25(1):1925.

[7] Courouce AM, Lee H, Drouet J, et al. Monoclonal antibodies to HBsAg: a study of their specificities for eight different HBsAg sub-types. Developments in Biological Standardization 1983;54:527-34.

[8] David GS, Present W, Martins J, et al. Monoclonal Antibodies in the detection of Hepatitis Infections. Medical Laboratory Science 1981;38:341-8.

[9] Fields HA, David CL, Bradley DW, et al. Experimental conditions affecting the sensitivity of enzyme-linked immunosorbent assay (ELISA) for detection of hepatitis B surface antigen (HBsAg). Bulletin of the World Health Organization 1983;61(1):135-42.

[10] Gang S, Mathur DR, Gang DK. Comparison of seropositivity of HIV, HBV, HCV and syphilis in replacement and voluntary blood donors in Western India. Indian J Pathol Microbiol 2001;44(4):409-12.

[11] Kaur H, Dhanao J, Oberoi A. Evaluation of rapid kits for detection of HIV, HBsAg and HCV infections. Indian J Med Sci 2000;54(10):432-4. 
[12] Nanu A, Sharma SP, ChatterJee K, et al. Markers for transfusion transmissible diseases in northern Indian voluntary and replacement blood donors: prevalence and trends 1989-1996. Vox Sang 1997;73(2):70-3.

[13] Torane VP, Shastri JS. Comparison of ELISA and rapid screening tests for the diagnosis of HIV, Hepatitis B and Hepatitis $\mathrm{C}$ among healthy blood donors in a tertiary care hospital in Mumbai. Indian J Med Microbio 2008;26(3):284-5.

[14] World Health Organization. Transfusion Medicine: Technical Manual. 2nd edn. New Delhi: Directorate General of Health Services, Ministry of Health and Family Welfare, Govt. of India 2003: p. 151.

[15] Hussain S, Patrick NA, Shams R. Hepatitis B and C prevalence and prevention awareness among health care workers in a tertiary care hospital. International Journal of Pathology 2010;8(1):16-21.

[16] Ali SA, Donahue RM, Qureshi H, et al. Hepatitis B and C in Pakistan: prevalence and risk factors. Int J Infect Dis 2009;13(1):9-19.

[17] Types of liver diseases: Chronic viral hepatitis. http://www.liverindia.com/chronic-hepatitis.php. 2013.

[18] Rao MB. The prevalence of hepatitis B in India and its prevention with Ayurveda-a revisit. Journal of New Approaches to Medicine and Health 2012;19(4):22-5.

[19] Dharmadhikari CA, Kulkarani RD, Kulkarani VA, et al. Incidence of hepatitis B surface antigen in liver diseases and voluntary blood donors. J Indian Med Assoc 1990;88(3):73-5.
[20] Arora U, Mann A. Prevalence of Hepatitis B virus, Hepatitis $C$ virus and HIV in patients of chronic liver disease in Amritsar. JIACM 2007;8(1):29-31.

[21] Nayak NC, Panda SK, Zuckerman AJ, et al. Dynamics and impact of perinatal transmission of hepatitis $B$ virus in North India. J Med Virol 1987;21(2):137-45.

[22] Lahariya C, Subramanya BP, Sosler S. An assessment of hepatitis B vaccine introduction in India: lessons for roll out and scale up of new vaccines in immunization programs. Indian J Public Health 2013;57(1):8-14.

[23] Karim ASS, Thejpal R, Singh B. High prevalence of hepatitis B virus infection in rural black adults in Mseleni, South Africa. Am J Public Health 1989;79(7):893-4.

[24] Khan TS, Rizvi F, Rashid A. Hepatitis C seropositivity among chronic liver disease patients in Hazara division, Pakistan. J Ayub Med Coll Abbottabad. 2003;15(2):53-5.

[25] Gupta S, Singh S. Occult hepatitis B virus infection in ART-naive HIV-infected patients seen at a tertiary care centre in north India. BMC Infect Dis 2010;10:53.

[26] Kumar A, Shukla I, Malik A. Co-infection with Hepatitis $B$ and immunodeficiency viruses in patients of liver disease. Indian J Med Microbiol 2003;21(2):141-2.

[27] Shantha S, Thyagarajan SP, Premavathy RK, et al. Correlation of autoimmune reactivity with hepatitis $\mathrm{B}$ and $\mathrm{C}$ virus (HBV and $\mathrm{HCV}$ ) infection in histologically proven chronic liver diseases. Indian J Med Microbiol 2002;20(1):12-5. 